\title{
Sistem Keamanan Pintu Berbasis Pengenalan Wajah Menggunakan Metode Fisherface
}

\section{Security System Based On Face Recognition Using Fisherface Method}

\author{
Bekti Maryuni Susanto $^{\# 1}$, Fendik Eko Purnomo ${ }^{\# 2}$,M. Faiq Ilman Fahmi ${ }^{\# 3}$

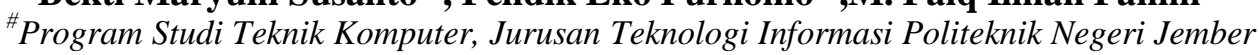 \\ Jl. Mastrip Kotak Pos 164 Jember Jawa Timur 68101 \\ ${ }^{1}$ bekti@polije.ac.id, \\ ${ }^{2}$ pfendikegmail.com, \\ ${ }^{3}$ faiq8ilman@gmail.com
}

\begin{abstract}
Crime is one of the classic problems faced big city. One type of crime that is rampant today is theft. Many thieves go home using a duplicate key or use a special way to unlock the door. Therefore we need a tool that is able to anticipate the occurrence of theft, a system that uses a special key. Key that only identical by the owner of the house, one of which is the face. In this final project created a door security system using facial recognition as a key to opening the door. The method used in this tool is the method fisherface. The primary step in the introduction of this face, that face detection, PCA calculation, calculation of FLD. The security system consists of three main parts: a webcam, microcontroller arduino uno, and laptops as database storage. Image of the user's face will be taken by using a webcam. Captured images are stored in the laptop database and matched with the existing database. The results will feed into the microcontroller arduino whether the door is open or locked.
\end{abstract}

Keywords: Door Security, Fisherface, Arduino

\section{PENDAhUluan}

Kegiatan sehari-hari kadang memaksa seseorang untuk meninggalkan rumah dalam keadaan kosong, seperti halnya di saat jam kerja ataupun sekolah. Hal ini mengakibatkan rumah menjadi rentan untuk dibobol dan terjadi tindakan pencurian, bahkan ketika rumah sudah terkunci atau tergembok dengan rapat. beberapa orang memang sangat mudah dan terampil untuk membuka kunci atau gembok hanya dengan seutas kawat kecil.

Berdasarkan dari kasus yang ada, maka harus difikirkan sebuah sistem baru yang berfungsi untuk mencegah tindak pembobolan dan pencurian rumah karena lemahnya tingkat pengaman kunci atau gembok. Sehingga terciptalah gagasan inovasi sistem keamanan pintu berbasis pengenalan wajah menggunakan metode fisherface tentunya memiliki keamanan yang lebih baik dibandingkan pengaman kunci atau gembok. Dapat dikatakan bahwa sistem ini adalah sebuah kunci elektronik yang otomatis. Sistem ini diharapkan dapat menanggulangi terjadinya tindak pencurian pada rumah-rumah yang sering ditinggalkan oleh penghuninya.

Saragih (2007) menyatakan bahwa pengenalan wajah (Face recognition) adalah salah satu teknik identifikasi teknologi biometrik dengan menggunakan wajah individu yang bersangkutan sebagai parameter utamanya. Secara garis besar proses pengenalan wajah terdiri dari tiga proses utama, yaitu deteksi wajah (face detection), Ektraksi ciri atau wajah (face atau feature extraction), Pengenalan wajah (face recognition). Secara umum, teknik dan metode dalam pengenalan wajah dapat dikelompokan ke dalam tiga pendekatan berdasarkan data yang dibutuhkannya, yaitu Pendekatan Holistik, Pendekatan feature-based, Pendekatan hybrid. Pada pendekatan holistik seluruh bagian atau ciri-ciri global wajah digunakan sebagai data masukan untuk pengenalan wajah misalnya eigenface, fisherface, nearest feature line (NFL), dan support vector machine (SVM). Pada pendekatan feature based wajah terbagi berdasarkan ciri-ciri lokal wajah seperti hidung, mulut, mata, dan lainnya yang kemudian digunakan sebagai data masukan 
misalnya Hidden Markov Model dan Dynamic Link Architecture. Pada pendekatan hybrid menggunakan seluruh bagian wajah dan ciri-ciri lokal wajah sebagai data masukan misalnya modular eigenface dan hybrid local feature.

Ada dua penelitian yang berkaitan dengan sistem keamanan pintu yaitu penelitian yang dilakukan oleh Bayu, Hendriawan, \& Susetyoko (2009) yang berjudul Penerapan Face Recognition Dengan Metode Eigenface dalam Intelligent Home Security. Peneliti menggunakan metode eigenface dan menggunakan kamera untuk menangkap gambar secara real time, dengan hasil yang menyatakan bahwa dari percobaan dan pengujian yang dilakukan, alat dapat mengenali citra wajah dengan tingkat keberhasilan sampai $87 \%$.

Helmi, Sumantri, \& Haritman (2013) yang berjudul Rancang Bangun Magnetic Door Lock Meggunakan Keypad dan Solenoid Berbasis Mikrokontroler Arduino Uno. Alat ini dirancang dengan memanfaatkan mikrokontroler Arduino Uno sebagai pengendali utama, dimana keypad berfungsi sebagai alat input kode password dan memberikan perintah pada mikrokontroler untuk mengendalikan relay. Alat ini bekerja ketika ada masukan berupa kode password melalui keypad, dan jika kode password yang dimasukkan benar maka mikrokontroler akan memberikan input high pada relay untuk mengaktifkan solenoid. Dari hasil pengujian yang telah dilakukan menunjukkan bahwa magnetic door lock ini dapat bekerja dengan baik, hal ini dibuktikan dengan software IDE Arduino bahwa mikrokontroler dapat mendeteksi input keypad dengan baik, delay yang diterapkan untuk mengaktifkan solenoid dapat berjalan dengan baik, dan fitur untuk mengubah dan menyimpan kode password baru dapat berjalan dengan baik.

Tujuan yang ingin dicapai dalam penelitian ini adalah untuk memperoleh gambaran tentang :

1. Mengimplementasikan alat keamanan pintu berbasis pengenalan wajah menggunakan metode fisherface.

2. Mengimplementasi menghubungkan antara aplikasi pengenalan wajah ke arduino uno $R 3$.

3. Mengimplementasikan unjuk kerja rancangan keamanan pintu menggunakan arduino uno R3.

Hasil penelitian ini diharapkan dapat bermanfaat bagi pihak-pihak sebagai berikut:

1. Memberikan tingkat keamanan yang lebih dalam pintu rumah.

2. Tercipta sebuah desain sistem keamanan pintu yang dapat dipertanggungjawabkan secara ilmiah, yang bermanfaat bagi masyarakat.

3. Penelitian ini dapat dimanfaatkan sebagai referensi dalam penelitian berikutnya.
Mengacu pada penelitian yang dilakukan oleh Bayu, Hendriawan, \& Susetyoko dan Helmi, Sumantri, \& Haritman, dapat digaris bawahi bahwa ada persamaan dan perbedaan keduanya. Kedua penelitian tersebut sama-sama menggunakan keamanan pintu sebagai objek penelitian, sedangkan perbedaan antara penelitian yang satu dengan yang lainnya adalah metode yang digunakan. Penelitian yang pertama menggunakan metode eigenface, sedangkan yang kedua menggunakan metode Keypad dan Solenoid Berbasis Mikrokontroler Arduino Uno. Penelitian yang akan penulis lakukan ialah tidak jauh berbeda dengan peneliti sebelumnya yaitu mengenai pintu sebagai objek penelitian yang terkait dengan cara pengamananya tetapi perbedaan yang penulis lakukan ialah terletak pada metodenya yaitu "Sistem keamanan pintu berbasis pengenalan wajah menggunakan metode fisherface".

\section{METODOLOGI}

Penelitian ini menerapkan metode pengenalan wajah (face recognition) fisherface untuk meningkatkan keamanan pada pintu. Proses training dan testing metode fisherface menggunakan $\mathrm{C \#}$ terhubung dengan arduino. Berdasarkan hasil training dan testing, solenoid akan membuka dan mengunci pintu rumah. Kendali solenoid menggunakan arduino yang mendapatkan input masukan dari proses training dan testing fisherface. Jika hasil testing fisherface sesuai dengan training maka arduino akan mengirimkan perintah untuk membuka pintu dan sebaliknya jika hasil testing unknown maka arduino mengirimkan bit untuk tetap mengunci pintu.

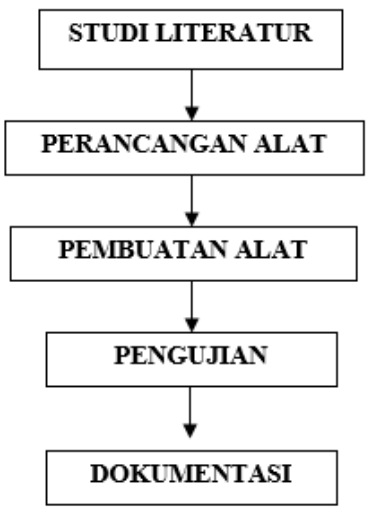

Gambar 1. Metode Kegiatan

Ada lima tahapan kegiatan dalam penelitian ini, yaitu studi literatur, perancangan alat, pembuatan alat, pengujian dan dokumentasi. Studi literatur dilakukan dengan pencarian referensi-referensi yang berkaitan dengan proyek yang akan dibuat, pencarian sumber seperti buku 
Bekti Maryuni Susanto, Fendik Eko Purnomo,M. Faiq Ilman Fahmi. Sistem Keamanan Pintu Berbasis Pengenalan Wajah Menggunakan Metode Fisherface

tutorial, website, jurnal ilmiah, dan data-data lain yang diperlukan dalam pengerjaan proyek tugas akhir sebgai awal kesiapan pengerjaan proyek. Penyiapan prangkat keras dan lunak yang digunakan termasuk dalam tahapan studi literatur ini.

TABel 1. PerangKat Keras yang Digunakan

\begin{tabular}{|l|l|l|}
\hline No. & Alat & Keterangan \\
\hline 1 & Solder & $40 \mathrm{~W}$ \\
\hline 2 & $\begin{array}{l}\text { Desoldering } \\
\text { Pump }\end{array}$ & Penyedot Timah \\
\hline 3 & Gergaji & - \\
\hline 4 & Tang & Tang Japit \\
\hline 5 & Obeng & Semua jenis obeng \\
\hline 6 & Multimeter & Alat ukur Voltase, Arus dll \\
\hline 7 & Penggaris & Penggaris Plastik \\
\hline 8 & Bor & - \\
\hline 9 & Laptop & Processor Intel Celeron \\
\hline 10 & Gerinda & - \\
\hline
\end{tabular}

TABEL 2. PERANGKat LUNAK YANG DigUnAKAN

\begin{tabular}{|l|l|l|}
\hline No. & Jenis & Keterangan \\
\hline 1 & Sistem Operasi & $\begin{array}{l}\text { Windows } \\
\text { Professional }\end{array}$ \\
\hline 2 & Aplikasi C\# & $\begin{array}{l}\text { Microsoft Visual C\# } \\
2010\end{array}$ \\
\hline 3 & Aplikasi Arduino & Arduino IDE 1.6.9 \\
\hline 4 & Aplikasi Office & $\begin{array}{l}\text { Microsoft Office } \\
2010\end{array}$ \\
\hline 5 & $\begin{array}{l}\text { Aplikasi pembuat } \\
\text { flowchart }\end{array}$ & Cacoo diagrams \\
\hline
\end{tabular}

TABEL 3. BAHAN YANG DIGUNAKAN

\begin{tabular}{|l|l|l|l|}
\hline No. & Bahan & Jumlah & Keterangan \\
\hline 1 & $\begin{array}{l}\text { Arduino } \\
\text { Board }\end{array}$ & 1 Buah & Arduino Uno R3 \\
\hline 2 & Modul Relay & 1 Buah & $\begin{array}{l}\text { Relay 1 Channel } \\
5 \mathrm{~V}\end{array}$ \\
\hline 3 & $\begin{array}{l}\text { Solenoid } \\
\text { Door Lock }\end{array}$ & 1 Buah & $12 \mathrm{~V}$ \\
\hline 4 & Webcam & 1 Buah & Logitech \\
\hline 5 & Led & 2 Buah & Merah dan hijau \\
\hline 6 & $\begin{array}{l}\text { Kabel USB } \\
\text { Serial }\end{array}$ & 1 Buah & - \\
\hline 7 & Adaptor & 2 Buah & $12 \mathrm{~V}, 5 \mathrm{~V}$ \\
\hline 8 & Kabel Jumper & 1 Pcs & $\begin{array}{l}\text { Male-Male dan } \\
\text { Male-Female }\end{array}$ \\
\hline 9 & Header & 20 Pin & - \\
\hline 10 & PCB Bolong & 1 Buah & - \\
\hline
\end{tabular}

\begin{tabular}{|l|l|l|l|}
\hline 11 & Baut \& Mur & 66 Buah & - \\
\hline 12 & Acrylic & $\begin{array}{l}1 \\
\text { Lembar }\end{array}$ & 1 Meter \\
\hline 13 & Timah & 1 Roll & $0.88 \mathrm{~mm}$ \\
\hline 14 & Alumunium & 3 Meter & - \\
\hline
\end{tabular}

Tahapan berikutnya adalah perancangan alat baik pernagkat keras maupun pernagkat lunak. Perangkat keras terdiri dari model pintu rumah yang dibuat dengan menggunakan akrilik, solenoid yang berfungsi untuk mengunci danmembuka kunci pintu serta kontroller menggunakan arduino yang dilengkapi dengan web cam.

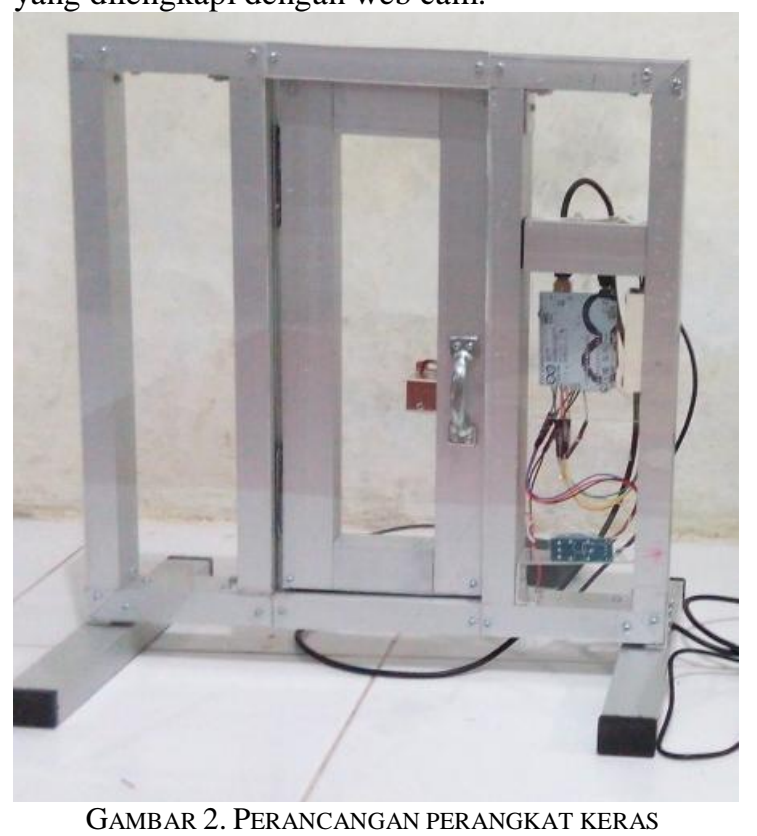

Solenoid adalah peralatan yang dipakai untuk mengkonversi sinyal elektrik atau arus listrik menjadi gerak mekanik. Solenoid dibuat dari kumparan dan inti besi yang dapat digerakkan, dan berfungsi sebagai aktuator untuk membuka kunci otomatis pada pintu kamar (Melalolin, 2013). Solenoid Door Lock adalah alat elektronik yang dibuat untuk dikhususkan untuk kendali tentang pintu, seperti pintu otomatis. Sekarang kebanyakan Solenoid Door Lock yang bekerjan dipasaran yaitu Solenoid Door Lock yang bekerja pada tegangan 12 V. dalam keadaan normal tuas pada Solenoid Door Lock memancang atau terkunci dan apabila diberi tegangan maka tuas akan memendek atau terbuka.

Selanjutnya perancangan perangkat lunak, yang berfungsi untuk melakukan training dan testing pengenalan wajah menggunakan metode fisherface. Perangkat lunak yang digunakan visual C\# dan arduino code. Gambar 3 menunjukkan 
proses ytaining fisherface menggunakan Visual C\#. Hasil tangkapan kamera web cam selanjutnya dilakukan pemotongan citra dan greyscale.

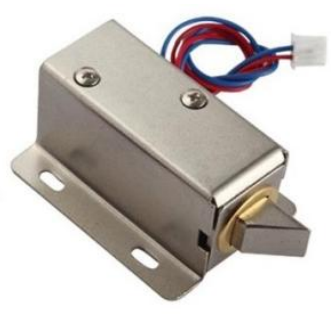

GAMBAR 3. SOLENOID DOOR LOCK

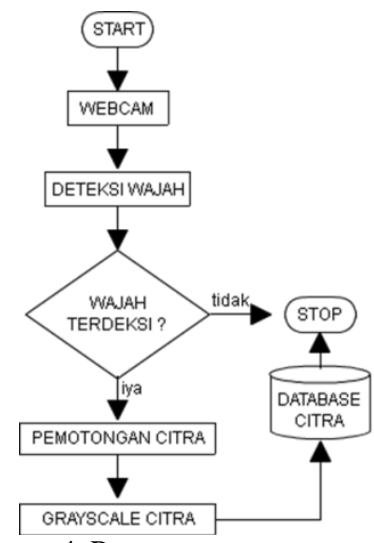

GAMBAR 4. PROSES TRAINING FISHERFACE

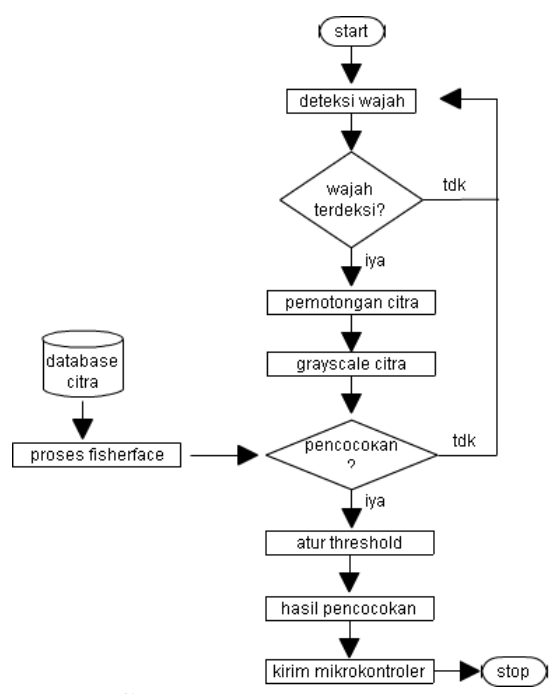

GAMBAR 5. PROSES PENCOCOKAN WAJAH

Gambar 4. Menunjukkan proses pencocokan citra menggunakan fisherface. Pencocokan berhasil jika citra sudah ditraining terlebih dahulu. Hasil pencocokan citra berupa caption yang sama saat proses training.

\section{III.HASIL DAN PEMBAHASAN}

Pada sistem keamanan pintu berbasis pengenalan wajah ini dengan menggunakan perangkat keras
(Hardaware) dan perangkat lunak (Software). Sistem ini di rancang untuk mengirim data digital yang dihasilkan oleh aplikasi pengenalan wajah ke modul arduino uno dan diproses dapat menggerakkan solenoid door lock

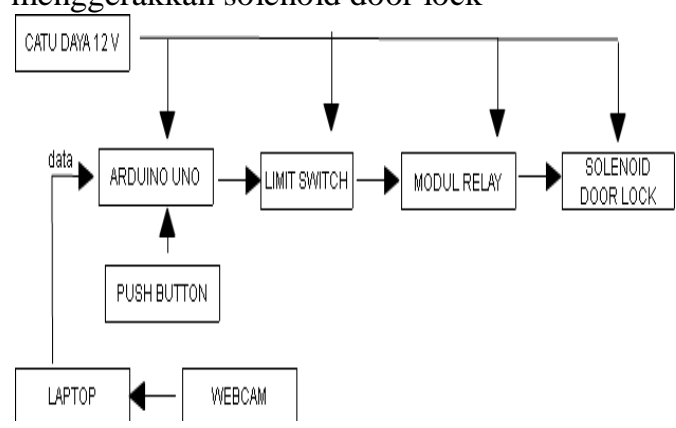

Cara melakukan training pengenalan wajah dalam penelitian ini dengan melakukan klik menu train pada tampilan utama aplikasi pengenalan wajh. Form training aplikasi pengenalan wajah pada laptop yang difungsikan untuk menyimpan dan memberi nama gambar yang telah terdeteksi, warna gambar diubah menjadi grayscale kemudian disimpan di folder TrainedFaces. Gambar form utama aplikasi pengenalan wajah pada laptop difungsikan untuk mencocokkan dan menampilkan nama gambar yang telah disimpan atau detraining dan untuk mengontrol pintu.

Dalam pengujian proses training citra wajah dengan cara memproses citra wajah dan menyimpannya ke dalam database, lalu mengekstraksi citra wajah menjadi karakteristik citra baru. Proses ini dimulai memilih menu train.Dari Gambar 5 ditunjukan proses penyimpanan data citra kedalam database, yang dimana database pada sistem ini berbentuk folder dengan kumpulan data citra wajah hasil penyelarasan. Data citra wajah tersebut disimpan dengan format face_nama_n.jpg, dimana face adalah nama konstanta dari citra wajah, nama adalah nama dari citra wajah dan $\mathrm{n}$ adalah nomor citra wajah yang dilatih. Proses ini, dilakukan pelatihan 5 pose yang berbeda. Berikut adalah gambar dengan 5 pose yang berbeda
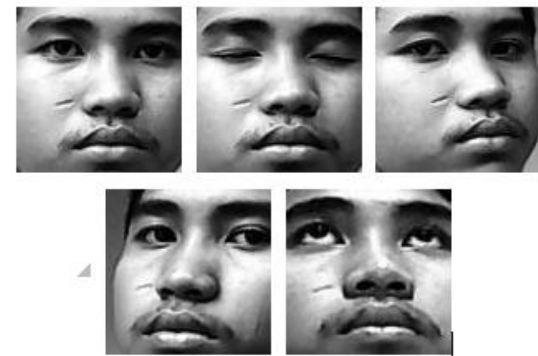

GAMBAR 6. WAJAH PELATIHAN DARI 1 ORANG DENGAN 5 POSE 
Bekti Maryuni Susanto, Fendik Eko Purnomo,M. Faiq Ilman Fahmi. Sistem Keamanan Pintu Berbasis Pengenalan Wajah Menggunakan Metode Fisherface

Pose yang digunakan untuk pelatihan adalah sebagai berikut :

1. Wajah normal

2. Wajah normal + menutup mata

3. Wajah dengan posisi menghadap kiri 20 derajat

4. Wajah dengan posisi menghadap kanan 20 derajat

5. Wajah dengan sedikit mendongak ke atas.

Setelah citra wajah disimpan ke dalam database, citra-citra wajah tersebut direkam ke dalam file 'TrainedLabels.xml', yang berisikan nama wajah orang yang dilatih dan directory file citra wajah. File ini nantinya akan digunakan dalam proses retrain untuk pelatihan ulang data baru yang ada dalam database.

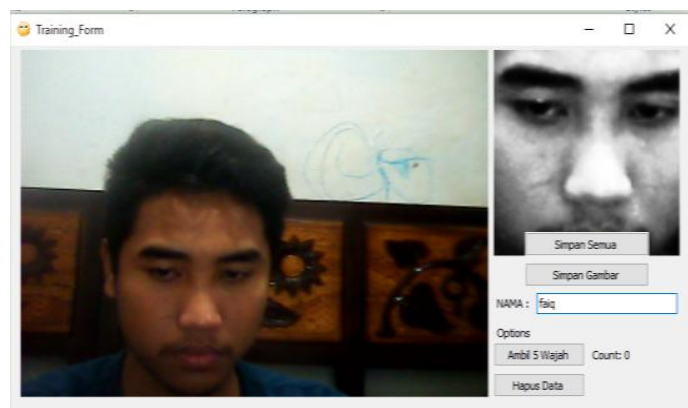

GAMBAR 7. FORM TRAINING PENGENALAN WAJAH

Setelah Melakukan training maka dilakukan proses pencocokan yang menampilkan caption nama wajah yang telah di inputkan pada form training. Proses pencocokan terdapat pada form utama aplikasi pengenalan wajah. Tetapi jika wajah tanpa melakukan proses training terlebih dahulu maka akan menampilkan caption 'Unknown' pada aplikasi form utama.

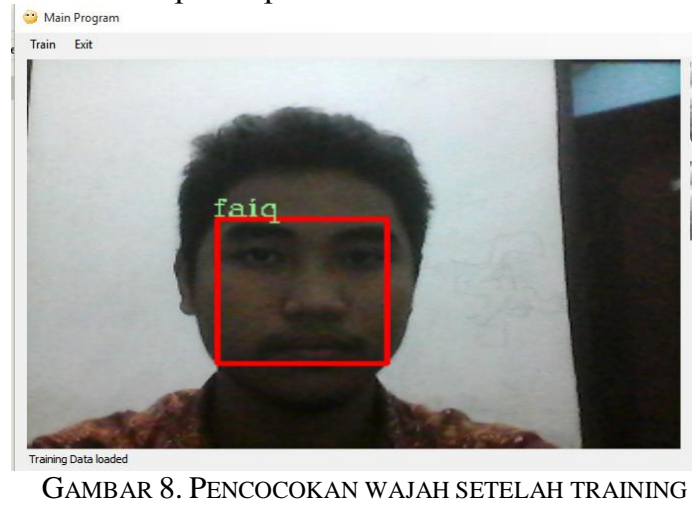

Jika pencocokan wajah dilakukan tanpa training maka akan muncul caption 'unknown' yang berarti wajah tidak dikenali. Ini digunakan untuk membedakan pemilik rumah dan bukan pemilik rumah.

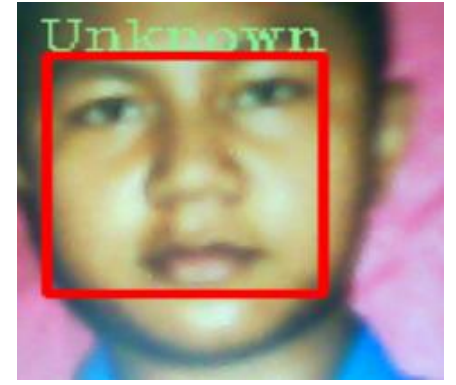

GAMBAR 9. PROSES PENCOCOKAN WAJAH TANPA TRAINING

Berdasarkan hasil pencocokan citra menggunakan fisherface, data akan dikirimkan ke mikrokontroller. Jika hasil pencocokan citra muncul nama caption yang sesuai pada saat proses training maka kontroler akan memerintahkan solenoid untuk membuka kunci pintu dan indikator lampu meyala hijau.

Untuk mengoperasikan pintu, data yang diakses atau dikirimkan dari aplikasi Pengenalan wajah pada Arduino Uno R3 seperti pada tabel 4.

\begin{tabular}{|l|l|}
\hline \multicolumn{2}{|c|}{ TABEL 4 DATA OPERASI PINTU } \\
\hline Data & Keterangan \\
\hline Serialport.Write(name) & $\begin{array}{l}\text { Kunci pintu akan } \\
\text { terbuka }\end{array}$ \\
\hline Serialport.Write(Unknown) & $\begin{array}{l}\text { Kunci pintu akan } \\
\text { terkunci }\end{array}$ \\
\hline
\end{tabular}

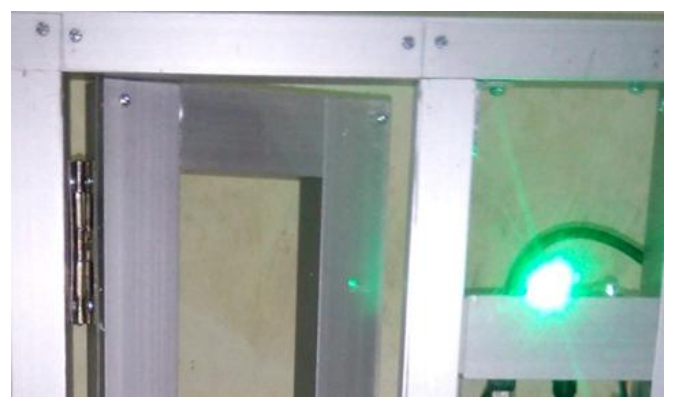

GAMBAR 10. INDIKATOR MENYALA HIJAU, KUNCI PINTU TERBUKA

Sebaliknya jika hasil pencocokan menunjukkan hasil Unknown maka pintu akan tetap terkunci dan lampu indikator menyala merah. 


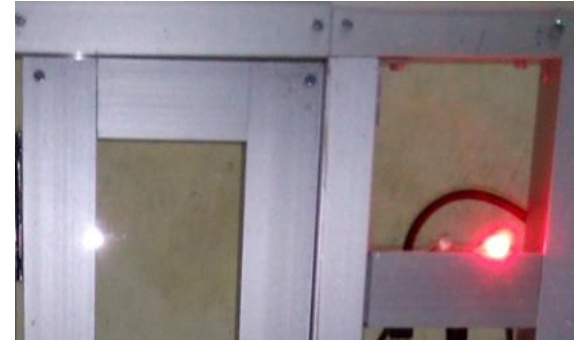

GAMBAR 11. INDIKATOR MENYALA MERAH, PINTU TERKUNCI

Pengujian dilakukan menggunakan 10 orang yang berbeda diantaranya 5 wajah orang dilakukan training atau pelatihan sedangkan 5 orang lainnya dilakukan tanpa training atau pelatihan seperti pada

TABEL 5. HASIL PENGUJIAN SISTEM

\begin{tabular}{|l|l|l|l|}
\hline Nama & Status & $\begin{array}{l}\text { Output } \\
\text { (Praktek) }\end{array}$ & $\begin{array}{l}\text { Output } \\
\text { (Teori) }\end{array}$ \\
\hline Faiq & Training & Terbuka & Terbuka \\
\hline Marsudi & Training & Terbuka & Terbuka \\
\hline Firda & Training & Tertutup & Terbuka \\
\hline Afidatul & Training & Tertutup & Terbuka \\
\hline Farhan & Training & Terbuka & Terbuka \\
\hline Fatih & $\begin{array}{l}\text { Tanpa } \\
\text { Training }\end{array}$ & Tertutup & Tertutup \\
\hline Rama & $\begin{array}{l}\text { Tanpa } \\
\text { Training }\end{array}$ & Tertutup & Tertutup \\
\hline Arif & $\begin{array}{l}\text { Tanpa } \\
\text { Training }\end{array}$ & Tertutup & Tertutup \\
\hline Heru & $\begin{array}{l}\text { Tanpa } \\
\text { Training }\end{array}$ & Tertutup & Tertutup \\
\hline Ardi & $\begin{array}{l}\text { Tanpa } \\
\text { Training }\end{array}$ & Tertutup & Tertutup \\
\hline
\end{tabular}

Keakuratan = (Jumlah Hasil Benar $/$ Jumlah Pengujian ) x 100\%

$=(8 / 10) \times 100 \%=80 \%$

Dalam tabel 4 pengujian alat terdapat 2 hasil atau output secara praktek yang salah yaitu pada nama Marsudi dan Ardi karena terlalu banyak data citra yang di simpan dan membutuhkan spesifikasi komputer yang bagus.

\section{IV.KESIMPULAN}

Kesimpulan yang dapat diambil dari pembuatan tugas akhir ini adalah:

1. Aplikasi pengenalan wajah dengan metode fisherface inidigunakan sebagai masukan untuk membuka dan mengunci pintu.

2. Dalam pembuatan alat keamanan pintu berbasis pengenalan wajah yaitu dengan menyiapkan aplikasi pengenalan wajah yang terdapat dilaptop, Board Arduino Uno R3, Solenoid Door Lock, modul Relay 1 Channel, limit switch, push button adaptor $12 \mathrm{~V}$, dan USB Serial.

3. Dalam melakukan pengenalan wajah harus dengan sinar yang cukup agar proses pendeteksian lebih akurat.

4. Dari 10 sample wajah yang diuji diantaranya 5 sample wajah yang di training dan 5 sample wajah tanpa di training, tingkat keberhasilannya ialah $80 \%$

Pada alat ini untuk mengubah orang membuka pintu harus dilakukan secara programing jadi kedepannya diperlukan fitur khusus agar user biasa dapat mengubah orang yang dapat membuka pintu.

\section{DAFTAR PUSTAKA}

[1] Agus kurniawan, R. A. (2004). Pengenalan Bahasa C\#. Anonim.2014. Pengertian Sistem. http://sisteminformasijemmyputra.blogspot.co.id/2014/02/pengertian -sistem.html[4 Mei 2015] [2] Bayu, S., Hendriawan, A., \& Susetyoko, R. (2009). Face Recognition Dengan Metode Eigenface dalam Intelligent Home Security. EEPIS. 1

[3] Dinata, Y. M. (2015). Arduino Itu Mudah. Jakarta: Elex Media Komputindo.

[4] Djunaidi, Feri. 2011. Pengenalan Arduino. Tanpakota.www.tokobuku.com

[5 ]Doni Tri. (2014).Motor Stepper Dan Selenoid http://bankidonk.blogspot.com/2014/02/motor-stepperdan-selenoid.html. [05 Mei 2015]

[6] Elektronika Dasar.(2103). Teori Relay Elektro Mekanikhttp://elektronika-dasar.web.id/teorielektronika/teori-relay-elektro-mekanik/. [05 Mei 2015]

[7] Helmi, G., Sumantri, Y., \& Haritman, E. (2013). Rancang Bangun Magnetic Door Lock Menggunakan Keypad dan Selenoid Berbasis Mikrokontroler Arduino Uno. ISSN 1412 - 3762 http://jurnal.upi.edu/electrans .

[8] Hendriono, D. 2014. Apa itu Arduino?. http://www.hendriono.com/blog/post/apa-itu-arduino [14 Desember 2014].

[9] Hermawati, F. A. (2013). Pengolahan Citra Digital : Konsep dan Teori. Andi Publisher.

[10] Indrajit, R. E. (2013). Pengertian Sistem Menurut Para Ahli.Retrieved from http://www.dysuryaputra.web.id/.[04 Mei 2015]

[11] Indrawan. (2010). Sistem, Model dan Simulasi http://indraaawan.blog.uns.ac.id. [05 Mei 2015]

[12] Masputz. 2015. Pengertian Adaptor, Fungsi dan JenisJenisnya. [30 Agustus 2015].

[13] Poerwadarminta, W.J.S.2007. Kamus Umum Bahasa Indonesia. Jakarta. Balai Pustaka.

[14] Purnama, Agus.(2013).Teori Relay Elektro Magnetik. http://elektronika-dasar.web.id/teori-elektronika/teorirelay-elektro-mekanik.[25 april 2015]

[15] Rahman, Rizal. (2012). Mengenal Microcontroller. https://rizqalrahman.wordpress.com/2012/07/12/menge nal-microcontroller.[25 april 2015]

[16] Saragih, Riko Arlando. (2007). Pengenalan Wajah Menggunakan Metode Fisherface. Fakultas Teknologi Industri - Universitas Kristen Petra , 50-62.

[17] Wicaksana, A dan Utama H.S. 2014. Membangun sistem keamanan pintu menggunakan rfid dan arduino severno. Yogyakarta. Sekolah tinggi manajemen informatika dan komputer amikom Yogyakarta. 
Bekti Maryuni Susanto, Fendik Eko Purnomo,M. Faiq Ilman Fahmi. Sistem Keamanan Pintu Berbasis Pengenalan Wajah Menggunakan Metode Fisherface 
Jurnal Ilmiah INOVASI, Vol. 17 No. 1 Edisi Januari - April 2017, ISSBN 1411-5549 
Bekti Maryuni Susanto, Fendik Eko Purnomo,M. Faiq Ilman Fahmi. Sistem Keamanan Pintu Berbasis Pengenalan Wajah Menggunakan Metode Fisherface 
